\title{
In situ synchrotron $X$-ray diffraction line-profile analysis of additively manufactured Ti-6Al-4V alloy under tensile deformation
}

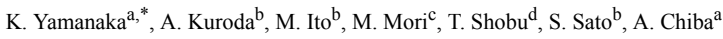 \\ ${ }^{\text {a }}$ Institute for Materials Research, Tohoku University, Sendai, Japan \\ ${ }^{\mathrm{b}}$ Graduate School of Science and Engineering, Ibaraki University, Hitachi, Japan \\ ${ }^{\mathrm{c}}$ Department of Materials and Environmental Engineering, National Institute of Technology, Sendai College, Natori, Japan \\ d Japan Atomic Energy Agency, Sayo, Japan \\ *k_yamanaka@imr.tohoku.ac.jp
}

\begin{abstract}
$\underline{\text { Abstract }}$
In this study, the tensile deformation behavior of an electron beam melted Ti-6Al-4V alloy was examined by in situ X-ray diffraction (XRD) line-profile analysis. The as-built Ti-6Al-4V alloy specimen showed a fine acicular microstructure that was produced through the decomposition of the $\alpha^{\prime}-$ martensite during the post-melt exposure to high temperatures. Using high-energy synchrotron radiation, XRD line-profile analysis was successfully applied for examining the evolution of dislocation structures not only in the $\alpha$-matrix but also in the nanosized, low-fraction $\beta$-phase precipitates located at the interfaces between the $\alpha$-laths. The results indicated that the dislocation density was initially higher in the $\beta$-phase and an increased dislocation density with increasing applied tensile strain was quantitatively captured in each constitutive phase. It can be thus concluded that the EBM Ti-6Al-4V alloy undergoes a cooperative plastic deformation between the constituent phases in the duplex microstructure. These results also suggested that XRD line-profile analysis combined with highenergy synchrotron XRD measurements can be utilized as a powerful tool for characterizing duplex microstructures in titanium alloys.
\end{abstract}

\section{Introduction}

There has been a strong interest in additive manufacturing (AM), also known as three-dimensional (3D) printing, as a revolutionized production route for industrial parts with complicated and/or optimized shapes. Among several metal AM processes that have been proposed so far, electron beam melting (EBM), a powder-bed-fusion AM process, is promising for fabricating more complicated geometries and realizing acceptable mechanical properties. Therefore, much attention has been given to EBM in various industries including aerospace and biomedical sectors.

EBM has already been applied successfully to titanium and titanium alloys. Previous researches reported that Ti-6Al-4V components prepared with EBM were found to exhibit tensile properties that are comparable or superior to those of conventional wrought material components [1-4]. In EBM system, a highenergy electron beam is selectively scanned over a metal powder bed to produce three-dimensional (3D) parts via stacking the series of thin melted layers, which represent two-dimensional (2D) slices produced from a 3D computer-added design (CAD) model, in a layer-by-layer manner. Therefore, the highly localized heat input and limited volume of the melt pool realize rapid cooling [4-9], resulting in a $\beta \rightarrow \alpha^{\prime}$ martensitic transformation in Ti-6Al-4V alloy during the EBM process $[9,10]$. On the other hand, apart from other AM processes, EBM is a completely hot process that maintains built products at elevated temperature, thereby allowing thermally activated processes such as grain growth [11] and phase transformation [12,13] to readily occur during fabrication. Therefore, the $\alpha^{\prime}$-martensite initially formed is decomposed into the acicular $\alpha+\beta$ stable microstructure during the post-melt exposure to high temperature. Such a complicated heat history, which consists of rapid cooling and subsequent exposure to high temperatures, is quite different from that in the conventional manufacturing process of $\mathrm{Ti}-6 \mathrm{Al}-4 \mathrm{~V}$ alloys. Therefore, an in-depth understanding on their deformation behavior is of crucial importance from both fundamental and practical viewpoints. 
In this study, we performed in situ synchrotron X-ray diffraction (XRD) measurements of an electron beam melted Ti-6Al-4V alloy during tensile deformation at room temperature to examine the plastic deformation behavior. XRD line-profile analysis was employed to capture the evolution of dislocation structure quantitatively.

\section{Material and experiments}

Ti-6Al-4V alloy specimens were additively manufactured by Arcam A2X system. Cylindrical rods with $18 \mathrm{~mm}$ in diameter and $160 \mathrm{~mm}$ in height were prepared on the stainless steel baseplate so that the build direction was parallel to the height of each component. The standard powders and build parameters, which were provided from the manufacturer, were employed for sample preparation. The electron beam power, scanning speed, and layer thickness were 240-1260 W, $\sim 500 \mathrm{~mm} \mathrm{~s}^{-1}$, and $50 \mu \mathrm{m}$, respectively, and the traveling direction of the beam was rotated by $90^{\circ}$ after each layer. The preheating temperature was set to $730^{\circ} \mathrm{C}$ and the sample temperature was monitored with thermocouples beneath the base plate.

All the experiments below were conducted on the as-built samples. Scanning electron microscopy (SEM) was performed on the samples using JEOL JXA$8430 \mathrm{~F}$ operated at an acceleration voltage of $15 \mathrm{kV}$. Electron backscatter diffraction (EBSD) measurements of the specimens were performed using a fieldemission scanning electron microscope (FESEM) (FEI XL30S-FEG) operated at $20 \mathrm{kV}$. The EBSD data were collected with a step size of $0.1 \mu \mathrm{m}$ in accordance with the magnification and analyzed using a TSL OIM system. Samples for SEM observations and EBSD analyses were ground with emery paper, polished with a $1 \mu \mathrm{m}$ alumina suspension, then finished with a mixture of $0.04 \mu \mathrm{m}$ colloidal silica suspension and $\mathrm{H}_{2} \mathrm{O}_{2}$ solution. Scanning transmission electron microscopy (STEM) observations and energy-dispersive X-ray spectroscopy (EDS) mappings were also conducted using an FEI TITAN ${ }^{3}$ G2 60-300 S/TEM operating at $300 \mathrm{kV}$ with a double spherical aberration (Cs) corrector. The TEM samples were prepared using a focused ion beam (FIB) device (FEI QUANTA $2003 \mathrm{D})$.

High-energy synchrotron XRD measurements were carried out at beamline BL22XU of the SPring-8, Japan. A schematic of the synchrotron XRD experimental setup is shown in Fig. 1. Samples with approximately $1 \mathrm{~mm}$ in thickness, $20 \mathrm{~mm}$ in gauge length, and $4 \mathrm{~mm}$ in gauge width were cut from the specimens using an electron discharge machining such that the incident X-ray beam was perpendicular to the longitudinal direction of the rods and the sample surfaces were finished with a $0.04-\mu \mathrm{m}$ colloidal silica suspension. The specimens were mounted on a diffractometer, and tensile deformation was induced in the specimens using a specially prepared load-cell. Diffraction patterns were acquired at a given tensile strain $(\varepsilon)$ using two-dimensional large-area pixel detectors (PILATUS 300K, DECTRIS) with sample-to-detector distances of $1557 \mathrm{~mm}$, respectively. The incident X-ray beam was focused to a spot size of approximately $500 \times 200 \mu \mathrm{m}$. The energy of the incident beam was estimated to be $30.036 \mathrm{keV}$, which was determined from the diffraction pattern of standard $\mathrm{CeO} \mathrm{O}_{2}$ powder. XRD line-profile analysis was carried out based on the multiple whole-profile (CMWP) method [14,15]. For the analysis for data obtained by conventional XRD, instrumental line profiles $\left(I_{i}\right)$ were obtained from standard $\mathrm{LaB}_{6}$ powder (SRM-660b, NIST). The CMWP fitting was performed using CMWP-fit, an open-source software obtained at the webpage http://csendes.elte.hu/cmwp/.

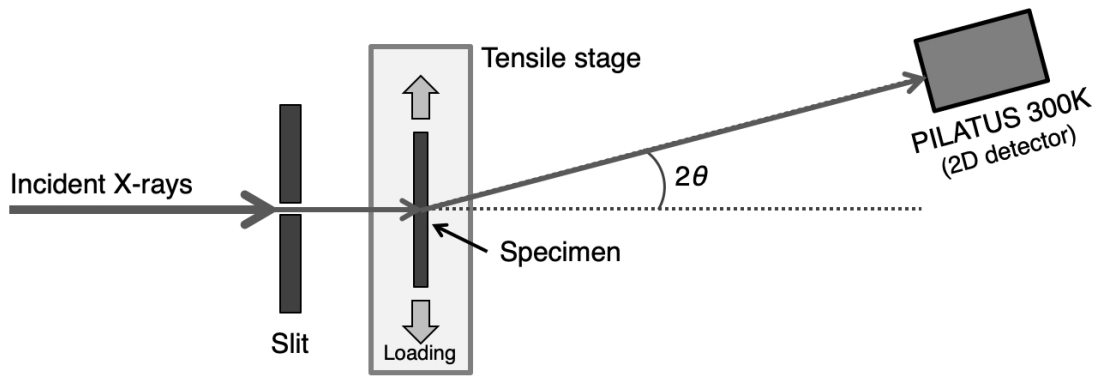

Figure 1. Schematic illustration of the experimental setup for synchrotron XRD measurements.

\section{$\underline{\text { Results and discussion }}$}


Figure 2(a) shows the backscattered electron (BSE) image of the as-built specimen, as observed at a cross section parallel to the longitudinal direction of the initial rod. The as-built specimen consisted of fine acicular microstructures produced within coarse columnar prior- $\beta$ grains. The nanosized $\beta$ phase, which corresponds to brighter areas in the BSE image, was identified at the interfaces of the $\alpha$-laths. The EBSD analysis revealed that the area fraction of the $\beta$-phase was as high as $2 \%$ in the as-built state, as shown in Fig. 2(b). Figure 2(c) shows the high-angle annular dark-field (HAADF)-STEM image and corresponding EDS maps for the as-built specimen. The interfacial $\beta$-precipitates was enriched with vanadium, while Al was depleted from them. It is generally difficult to examine the evolution of dislocations in such fine $\beta$-phase precipitates using conventional characterization techniques.
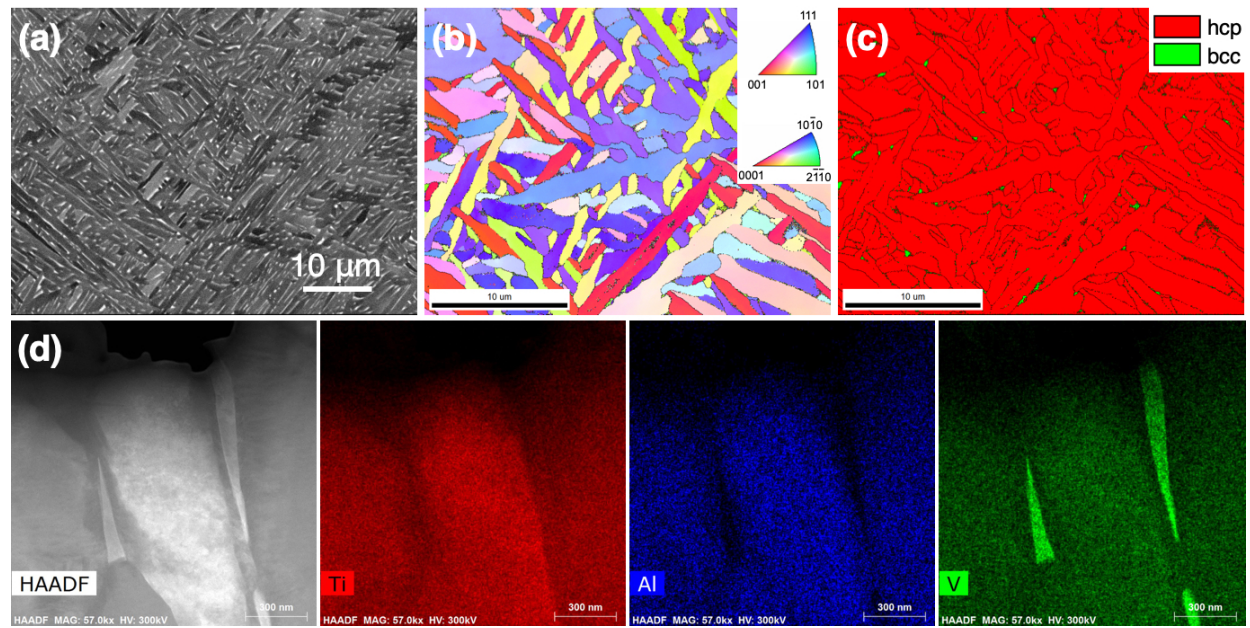

Figure 2. (a) BSE image, (b) IPF map, (c) phase map, and (d) HAADF-STEM image with the corresponding EDS mappings for the as-built Ti-6Al-4V alloy specimen.

Figure 3(a) shows the evolution of the diffraction intensity for the as-built specimen during tensile loading at room temperature, as obtained in in situ synchrotron XRD measurements. The diffraction peaks for both $\alpha$ - and $\beta$-phases became broader with increasing applied tensile strain, indicating that evolution of dislocation structure occurred in both constitutive phases simultaneously. It should be noted that the diffraction peaks of the $\beta$-phase, which are difficult to detect in conventional XRD measurements, were successfully captured using high-energy synchrotron radiation. Figures 3(b) and (c) represent the results of the CMWP fitting for the as-built specimens at $\varepsilon=0$ and $\varepsilon=0.1455$, respectively. The line profiles extracted from the 2D diffraction patterns were well fitted with the CMWP procedure.

(a)

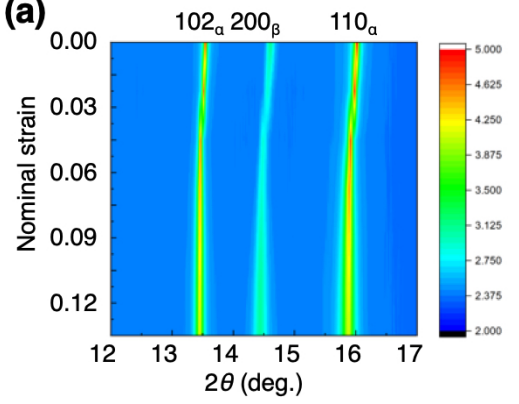

(b)

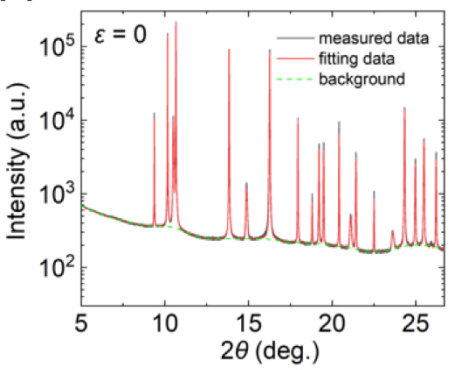

(c)

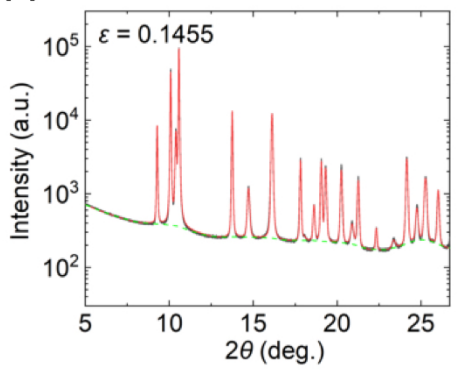

Figure 3. (a) Evolution of diffraction intensity as a function of tensile strain and the CMWP fitting results for the as-built Ti- $6 \mathrm{Al}-4 \mathrm{~V}$ alloy specimen at (b) $\varepsilon=0$ and (c) $\varepsilon=$ 
Figure 4 shows the CMWP fitting results for the as-built Ti-6 Al-4V alloy specimen, plotted as a function of tensile strain. The result revealed that the dislocation density $(\rho)$ obtained in the as-built state $(\varepsilon=0)$ was approximately one order higher than that for the surrounding $\alpha$-matrix (Fig. 4(a)). This is interesting because the $\beta$-phase was produced during the post-melt procedure and had not been subjected to plastic deformation. It was also found that the dislocation density values for both $\alpha$ - and $\beta$-phases increased simultaneously during tensile deformation.

The dislocation arrangement can be evaluated using the CMWP fitting with a suitable dimensionless parameter $M$ [16]:

$$
M=R_{e} \sqrt{\rho}
$$

where $R_{e}$ is effective outer cutoff radius of dislocations. An $M$ value lower than 1 corresponds to a stronger correlation between the dislocations [17]. The $M$ value tended to decrease with increasing $\varepsilon$, suggesting that the interaction between dislocations becomes stronger during tensile deformation. A similar trend can be observed in both phases. However, the fact that the values were larger than 1 indicates that dislocations were randomly distributed in the present specimen even after tensile loading.

Finally, the area-averaged crystallite size $\left(\langle x\rangle_{\text {area }}\right)$, which is defined as the size of the domains that coherently diffract incident $\mathrm{X}$-rays, and the coherent domains for X-ray scattering (dislocation arrays, subgrains, cell structures, etc. [14]), is presented in Fig. 4(c). In general, the crystallite sizes were as large as the microstructural length scales of each phase. The obtained $\langle x\rangle_{\text {area }}$ value was slightly larger in the $\alpha$-phase and decreased with increasing tensile strain.

The results mentioned above suggest a cooperative deformation behavior in the EBM-built Ti-6Al-4V alloy with an acicular microstructure, although the more detailed analysis is required to clarify the underlaying mechanisms. Moreover, the synchrotron XRD line-profile analysis employed in this study is a powerful tool for characterizing fine duplex microstructures in additively manufactured titanium alloys as well as those produced in conventional processing.

(a)

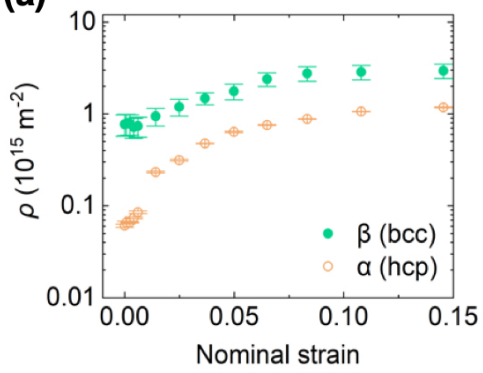

(b)

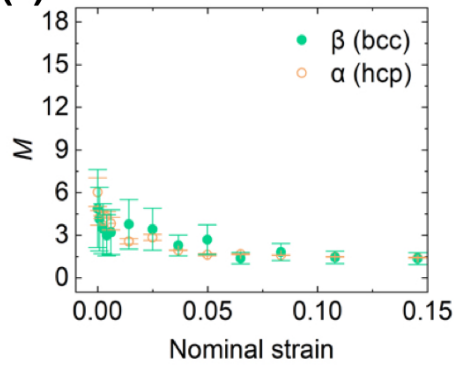

(c)

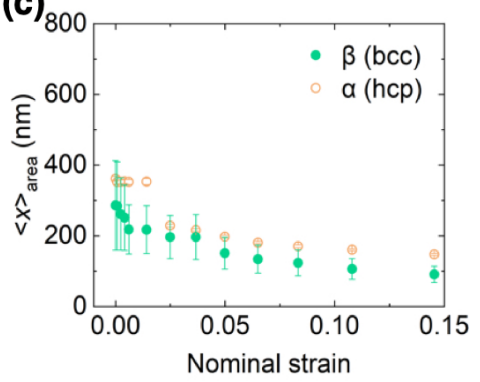

Figure 4. Results of XRD line-profile analysis based on the CMWP fitting for the as-built Ti-6Al-4V alloy specimens: (a) dislocation density ( $\rho$ ), dislocation configuration parameter $(M)$, and crystallite size $\left(\langle x\rangle_{\text {area }}\right)$.

\section{$\underline{\text { Conclusion }}$}

In this study, we prepared cylindrical Ti-6 Al-4V alloy samples using EBM and examined their dislocation structure as a function of tensile strain. Highenergy synchrotron radiation enabled us to capture the diffraction peaks not only for the $\alpha$-matrix but also for the nanosized, low-fraction $\beta$-phase precipitates. By combining in situ synchrotron XRD measurements with line-profile analysis, it was successfully captured that the as-built Ti-6Al-4V alloy with a fine acicular $\alpha+\beta$ microstructure undergoes a cooperative deformation behavior between the constitutive phases. These results suggest that synchrotron XRD lineprofile analysis is a powerful tool for characterizing duplex microstructures in additively manufactured titanium alloys.

\section{Acknowledgement}


This research was supported by the Grant-in-Aid for Young Scientists (A) [No. 17H04957] from the Japan Society for the Promotion of Science (JSPS); the Research Grant for Young Scholars funded by Yamanashi Prefecture, Japan; the Iron and Steel Institute of Japan; and the Light Metal Educational Foundation, Inc. The synchrotron radiation experiments were performed at the BL22XU of SPring-8 with the approval of the Japan Synchrotron Radiation Research Institute (JASRI) and Japan Atomic Energy Agency (JAEA) (Proposal No. 2017A3740_2017AE13).

\section{$\underline{\text { References }}$}

[1] L.E. Murr, E.V. Esquivel, S.A. Quinones, S.M. Gaytan, M.I. Lopez, E.Y. Martinez, F. Medina, D.H. Hernandez, E. Martinez, J.L. Martinez, S.W. Stafford, D.K. Brown, T. Hoppe, W. Meyers, U. Lindhe, R.B. Wicker, Mater. Charact. 60 (2009) 96.

[2] X. Zhao, S. Li, M. Zhang, Y. Liu, T.B. Sercombe, S. Wang, Y. Hao, R. Yang, L.E. Murr, Mater. Des. 95 (2015) 21.

[3] H. Gong, K. Rafi, H. Gu, G.D.D. Janaki Ram, T. Starr, B. Stucker, K. Ra, H. Gu, G.D.J. Ram, T. Starr, B. Stucker, K. Rafi, H. Gu, G.D.D. Janaki Ram, T. Starr, B. Stucker, Mater. Des. 86 (2015) 545.

[4] X. Tan, Y. Kok, Y.J. Tan, M. Descoins, D. Mangelinck, S.B. Tor, K.F. Leong, C.K. Chua, Y. Jun, M. Descoins, D. Mangelinck, S.B. Tor, K. Fai, C. Kai, Y.J. Tan, M. Descoins, D. Mangelinck, S.B. Tor, K.F. Leong, C.K. Chua, Acta Mater. 97 (2015) 1.

[5] L. Thijs, F. Verhaeghe, T. Craeghs, J. Van Humbeeck, J.-P.P. Kruth, Acta Mater. 58 (2010) 3303.

[6] S.S. Al-Bermani, M.L. Blackmore, W. Zhang, I. Todd, Metall. Mater. Trans. A 41 (2010) 3422.

[7] T. Vilaro, C. Colin, J.D. Bartout, Metall. Mater. Trans. A 42 (2011) 3190.

[8] W. Xu, M. Brandt, S. Sun, J. Elambasseril, Q. Liu, K. Latham, K. Xia, M. Qian, Acta Mater. 85 (2015) 74.

[9] X. Tan, Y. Kok, W.Q. Toh, Y.J. Tan, M. Descoins, D. Mangelinck, S.B. Tor, K.F. Leong, C.K. Chua, Sci. Rep. 6 (2016) 26039.

[10] K. Yamanaka, M. Mori, A. Chiba, in:, V. Venkatesh, A.L. Pilchak, J.E. Allison, S. Ankem, R. Boyer, J. Christodoulou, H.L. Fraser, M.A. Imam, Y. Kosaka, H.J. Rack, A. Chatterjee, A. Woodfield (Eds.), Proc. 13th World Conf. Titan., John Wiley \& Sons, Inc., Hoboken, 2016 , pp. 1289-1293.

[11] K. Yamanaka, W. Saito, M. Mori, H. Matsumoto, S. Sato, A. Chiba, Materialia 6 (2019) 100281.

[12] S.H. Sun, Y. Koizumi, S. Kurosu, Y.P. Li, A. Chiba, Acta Mater. 86 (2015) 305.

[13] W.J. Sames, K.A. Unocic, G.W. Helmreich, M.M. Kirka, F. Medina, R.R. Dehoff, S.S. Babu, Addit. Manuf. 13 (2017) 156.

[14] T. Ungár, J. Gubicza, G. Ribárik, A. Borbély, T. Ung, J. Gubicza, G. Rib, A. Borb, T. Ungár, J. Gubicza, G. Ribárik, A. Borbély, J. Appl. Crystallogr. 34 (2001) 298 .

[15] G. Ribárik, J. Gubicza, T. Ungár, Mater. Sci. Eng. A 387-389 (2004) 343.

[16] M. Wilkens, Acta Metall. 17 (1969) 1155.

[17] M. Wilkens, in:, J. Simmons, R. DeWit, R. Bullough (Eds.), Fundam. Asp. Dislocation Theory Conf. Proceedings, Natl. Bur. Stand. April 21-25, 1969, U.S. National Bureau of Standards, Washington DC, 1970, pp. 1195-1221. 